\title{
Desain pin hole mempengaruhi kuat rekat geser gigitiruan jembatan adesif Pin hole design affect shear bond strength of adhesive bridge
}

\author{
${ }^{1}$ Edy Machmud, ${ }^{1}$ Moh. Dharmautama, ${ }^{2}$ Herawati \\ ${ }^{1}$ Bagian Prostodonsia Fakultas Kedokteran Gigi Universitas Hasanuddin, Makassar \\ ${ }^{2}$ PDGS Prostodonsia Fakultas Kedokteran Gigi Universitas Hasanuddin/RSUD Djafar Harum Lasusua Kolaka Utara \\ Indonesia
}

\begin{abstract}
To overcome the failure of adhesive bridge due to release of the adhesive bond cement between teeth and metal, preparation modification was performed with a pin hole in the teeth cingulum. This study aimed to determine the effect of thread on a pin hole to shear strength adhesion of adhesive bridge. Forty maxillary incisors were prepared at their palatinal surfaces $0.3 \mathrm{~mm}$ thick, and were divided into four treatments (threaded hole + threaded pin, threaded holes + non-threaded pin, non-threaded holes + threaded pin, non-threaded holes + non-threaded pin). Casted-plates made from nickel chromium alloy were cemented to the palatal surface of the tooth with adhesive cement (Panavia TMF 2.0), and then adhesion shear strength tested. The test and evaluation of the residual cement on the surface were performed in Laboratory Metallurgy, Department of Engineering ITB. Data were analyzed by one-way ANOVA test ( $p=0.05)$. Adhesion shear strength of plate with threaded holes+threaded pin has the highest retention. Residual cement on threaded hole+threaded pin plates similar to threaded hole+non-threaded pin, but more than any other groups. the conclusions were, the adhesion shear strength depends on the design of pin hole. The wider surface of cement remaining on the plates, the greater adhesion shear strength.
\end{abstract}

Keywords: retention design, pin holes, adhesive bridge, shear bond strength, adhesive cement

\begin{abstract}
ABSTRAK
Untuk mengatasi kegagalan gigitiruan jembatan (GTJ) adesif akibat lepasnya ikatan semen antara gigi dengan logam, dibuat desain preparasi dengan modifikasi pin hole pada singulum gigi. Penelitian ini ditujukan untuk mengetahui pengaruh ulir pada pin hole terhadap kuat rekat geser GTJ adesif. Empat puluh pasang sampel gigi insisivus rahang atas dipreparasi permukaan palatalnya setebal $0,3 \mathrm{~mm}$, lalu dibagi menjadi empat perlakuan (hole ulir+pin ulir, hole ulir+pin tanpa ulir, hole tanpa ulir+pin ulir, hole tanpa ulir+pin tanpa ulir). Lempeng hasil tuangan dari bahan aloi nikel kromium disemen ke permukaan palatal gigi dengan semen adesif (Panavia ${ }^{\mathrm{TM}} \mathrm{F}$ 2.0), lalu diuji kuat rekat gesernya. Uji dan pemeriksaan semen pada permukaan dalam lempeng dilakukan di Laboratorium Metalurgi Jurusan Mesin ITB. Data dianalisis dengan uji ANOVA satu arah $(\mathrm{p}=0,05)$. Hasilnya, kuat rekat geser lempeng dengan hole berulir+pin berulir mempunyai retensi lebih yang tertinggi. Dengan pemeriksaan stereomikroskop, sisa semen pada lempeng dengan hole berulir+pin berulir hampir sama dengan hole berulir+pin tanpa ulir, dan lebih banyak dari kelompok lain. Simpulannya, kuat rekat geser semen adesif pada permukaan logam tergantung pada desain retensi pin hole yang diberikan ulir. Semakin luas permukaan semen yang masih tersisa pada permukaan lempeng, makin besar pula kuat rekat geser semen adesifnya.
\end{abstract}

Kata kunci: desain retensi, pin hole, gigitiruan jembatan adesif, kuat rekat geser, semen adesif

Koresponden: Herawati, E-mail: herawatineesa@yahoo.com

\section{PENDAHULUAN}

Gigitiruan jembatan cekat (GTJ) adalah piranti prostodontik yang direkatkan secara permanen pada gigi-gigi penyangga yang telah dipreparasi dengan menggunakan semen,untuk menggantikan satu atau lebih gigi. Restorasi satu gigi dapat mengembalikan fungsi secara utuh, dan termasuk efek kosmetik. Salah satu alternatif GTJ adalah GTJ adesif yang merupakan salah satu pilihan yang banyak diminati oleh pasien. Restorasi GTJ adesif menjadi pilihan bagi sebagian besar masyarakat karena merupakan restorasi cekat yang pengambilan struktur giginya relatif sedikit.

Kegagalan restorasi GTJ adesif yang sering dijumpai dalam praktek klinik sehari-hari adalah terlepasnya restorasi.Terlepasnya GTJ adesif terjadi akibat lepasnya ikatan antara semen resin adesif dengan permukaan gigi atau lepasnya ikatan antara semen adesifdengan permukaan logam. Sehubungan hal tersebut, pemilihan gigi penyangga dan desain preparasi gigi penyangga menentukan keberhasilan GTJ adesif, selain jenis semen yang digunakan.

Pertimbangan mekanis preparasi gigi penyangga adalah salah satu faktoryang perlu diperhatikan selain luas permukaan dan kekasaran permukaan preparasi gigi. Yang ter penting bentuk dari desain preparasi itu sendiri yang dapat memberikan suatu retensi dan resistensi terhadap terlepasnya suatu restorasi. ${ }^{2}$

Kurangnya retensi menjadi penyebab umum kegagalan GTC. Menurut Assif dkk yang dikutip 
oleh Ayad,dilaporkan bahwa retensi dapat diperbaiki melalui ikatan mekanis dari semen, dan adanya hubungan langsung antara retensi dengan permukaan daerah yang tertutup semen, yaitu permukaan gigi dan permukaan logam. Faktor-faktor tersebut dapat mempengaruhi distribusi tekanan dalam permukaan lapisan semen,efisiensi ikatan semen terhadap kedua permukaan yang saling berikatan, dan daya tahan semen, termasuk resistensi jangka panjang terhadap gangguan dan lepasnya ikatan mekanis. Sedangkan menurutKaufman dan Loreyyang dikutip oleh Ayad, dikatakan bahwa peningkatan kekasaran permukaan preparasi gigi akan menambah retensi logam cor yang disemen, karena terjadi penambahan ikatan mekanis bahan semen dengan permukaan gigi yang kasar. Ridwan yang dikutip oleh Ayad, menyatakan bahwa adanya korelasi yang nyata antara kekasaran permukaan preparasi gigi dengan besarnya retensi yang dihasilkan. Ayad dkk, dalam penelitiannya melaporkan hubungan signifikan secara statistik antara kekasaran permukaan dentin dan retensi dari preparasi gigi menambah ikatan mekanis semen sehingga meningkatkan retensi. ${ }^{2}$

Kekasaran permukaan preparasi gigi umumnya meningkatkan retensi dengan penggunaan semen zink fosfat, akan tetapi efeknya dengan semen adesif, polikarboksilat, glass ionomer, dan resin, belum diketahui secara jelas. ${ }^{3}$

Luas permukaan preparasi sangat berpengaruh terhadap retensi dan resistensi restorasi, sedangkan pada pembuatan GTJ adesif hanya dibutuhkan relatif sedikit pengambilan struktur jaringan gigi, sehingga memerlukan retensi tambahan berupa desain preparasi pin hole berulir pada gigi penyangga untuk menambah kekuatan retensi GTJ adesif pada gigi anterior dan gigi posterior berupa bentuk boks. Hal ini tersebut didukung oleh Kayser yang dikutip Ridwan yang mengatakan retensi mahkota logam tuang ditentukan oleh beberapa faktor, yaitu luasnya permukaan gigi yang disemen, kemiringan dinding preparasi, kekerasan dan kekakuan logam, semen yang digunakan,kekasaran permukaan preparasi gigi, retensi tambahan berupa pin, boks, dan groove. ${ }^{4}$

Berdasarkan masalah di tersebut, perlu diteliti pengaruh bentuk preparasi yang menggunakan pin hole dengan penambahan ulir untuk menambah retensi lempeng yang direkatkan dengan semen adesif.

\section{BAHAN DAN METODE}

Penelitian eksperimental laboratorium in vitro dengan pendekatan deskriptif dan komparatif, serta menggunakan rancangan analisis statistik one way ANOVA dengan menggunakan statistik $\mathrm{F}$.

\section{Tahap Persiapan}

Gigi insisivus sentralis rahang atas dibersihkan, ditanam dalam balok resin (Hillon $\left.{ }^{\circledR}\right)$ sampai batas servikal gigi dalam posisi sejajar sumbu gigi (gambar 1). Setelah itu permukaan gigi dibersihkan dari sisasisa bahan organik dengan rubber cap dan pumis, kemudian dibilas air sampai bersih.

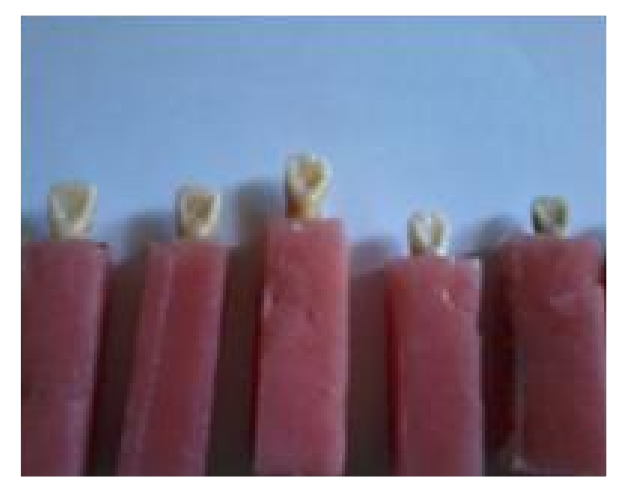

Gambar1 Gigi model preparasi pada balok resin akrilik

\section{Tahap penelitian}

Penelitianmenggunakan 40 buah gigi yang pada permukaan palatalnya dipreparasi sedalam $0,3 \mathrm{~mm}$ denganburintan wheel(Edenta) dan dibuat preparasi hole sedalam 0,3 mmdengan burintan fissure (Edenta). Selanjutnya, dibuat pola malam (Dental Inlay Casting Wax GC Corp. Tokyo, Japan) dan lempeng logam yang disemen ke permukaan preparasi menggunakan semen adesif(Panavia ${ }^{\text {TMF }}$ 2.0), direndam dalam saliva buatan (Marzher \& Screber; Selulose $1 \mathrm{~g}$, sorbitol 3 g, KCL 0,12 g, $\mathrm{NaCl}_{2} \cdot 6 \mathrm{H}_{2} \mathrm{O} 0,05 \mathrm{~g}, \mathrm{CaCl}_{2} \cdot 2 \mathrm{H}_{2} \mathrm{O}$ $0,015 \mathrm{~g}, \mathrm{~K}_{2} \mathrm{HPO}_{4} 0,034 \mathrm{~g}$, akuades $100 \mathrm{ml}$ ) selama 24 jam dan suhu $37^{\circ} \mathrm{C}$. Ujikuatrekatgeser dilakukan dengan alat universal testing machine (Model 119, Instron Corp. Canton, Mass), dan untuk pemeriksaan semen yang masih merekat pada permukaan dalam lempeng logam dengan alat stereomikroskop di Laboratorium Metalurgi Jurusan Mesin Institut Teknologi Bandung.

Sampel dibagi menjadi empat kelompok, yaitu kelompok hole tanpa ulir+pin tanpa ulir, kelompok hole dengan ulir+pin tanpa ulir, kelompok hole tanpa ulir+pin dengan ulir, dan kelompok hole dengan ulir+pin dengan ulir

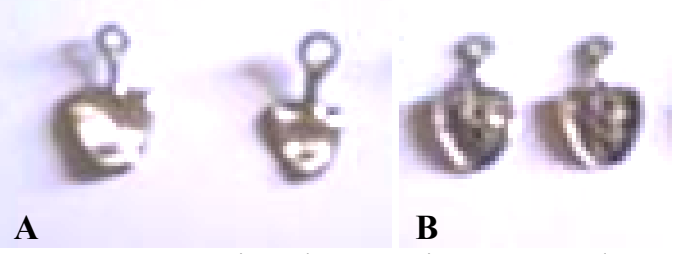

Gambar 2 Retainer logam+pin; A permukaan polis, $\mathbf{B}$ permukaan anatomis 
Uji kuat rekat geser dan penilaian sisa semen pada permukaan logam

Kuat rekat geser ataushear bond strength adalah kekuatan yang tercatat saat suatu benda terlepas dari ikatannya, oleh suatu gaya yang menarik atau sejajar dengan perekatannya. ${ }^{7}$ Pembebanan gaya dilakukan dengan menggunakan Instron Universal Testing Machine (Model 1195, Instron Corp.Canton, Mass) dengan kecepatan $0,5 \mathrm{~mm} /$ menit. Kuat rekat geser merupakan hasil bagi dari besar gaya $(\mathrm{F})$ terhadap luas perekatan yang diuji (A). $\lambda=F \cdot A^{-1} . F=$ beban (L) $\mathrm{x}$ gravitasi $(\mathrm{g})$

Setelah masing-masing lempeng logam terlepas dari permukaan gigi, dilakukan pemeriksaan dan pemotretan permukaan dalam lempeng dengan menggunakan stereomikroskop dan film KodakASA 200 (pembesaran 38x). Pada hasil pemotretan, sisa semen adesif diperiksa dan dinilai dengan skor adhesive remnant index (ARI) yang diperkenalkan oleh ArtundanBergland 4, yaitu $0=$ tidak ada semen pada permukaan logam, $1=$ kurang dari $1 / 2$ semen merekat pada permukaan logam, $2=$ lebih dari $1 / 2$ semen merekat pada permukaan logam, dan $3=$ semua semen merekat pada permukaan logam.

\section{HASIL}

Tabel 1 menunjukkan adanya perbedaan kuat rekat geser dari setiap perlakuan. Tampak kuat rekat geser lempeng dengan pin berulir dan hole berulir lebih besar dari pada ketiga bentukan lainnya.

Pada tabel 2 tampak uji kesamaan rata-rata kuat rekat geser dari keempat perlakuan dengan uji ANOVA. Terlihat bahwa hasil pengujian bersifat bermakna dengan $F_{\text {hitung }}=5,79>F_{\text {tabel }}=4,38$. Hal ini menunjukkan adanya perbedaan kuat rekat geser dari keempat perlakuan.

Oleh karena berdasarkan uji ANOVA terdapat hasil yang berbeda bermakna, maka dilanjutkan dengan uji rentang Neman Keuls untuk melihat perbedaan dari keempat perlakuan (tabel 3).

Tabel 1 Hasil uji tarik kuat rekat geser $(\mathrm{MPa})$

\begin{tabular}{ccccc}
\hline Perlakuan & $\begin{array}{c}\text { Hole } \text { ulir+ } \\
\text { pin ulir }\end{array}$ & $\begin{array}{c}\text { Hole ulir+ } \\
\text { pin tanpa ulir }\end{array}$ & $\begin{array}{c}\text { Hole tanpa ulir+pin } \\
\text { ulir }\end{array}$ & $\begin{array}{c}\text { Hole tanpa ulir+ } \\
\text { pin tanpa ulir }\end{array}$ \\
\hline Sampel 1 & 0,977 & 0,875 & 0,887 & 0,768 \\
Sampel 2 & 0,976 & 0,899 & 0,898 & 0,887 \\
Sampel 3 & 0,987 & 0,898 & 0,997 & 0,779 \\
Sampel 4 & 0,993 & 0,994 & 0,898 & 0,786 \\
Sampel 5 & 0,987 & 0,997 & 0,865 & 0,889 \\
Sampel 6 & 0,998 & 0,897 & 0,877 & 0,758 \\
Sampel 7 & 0,999 & 0,899 & 0,888 & 0,876 \\
Sampel 8 & 0,987 & 0,912 & 0,895 & 0,798 \\
Sampel 9 & 1,012 & 0,986 & 0,901 & 0,877 \\
Sampel 10 & 0,998 & 0,976 & 0,987 & 0,891 \\
\hline Rerata & 0,9914 & 0,9333 & 0,8309 \\
Std & 0,010926 & 0,048433 & 0,04093 & 0,057113 \\
N & 10 & 10 & 10 & 10 \\
\hline
\end{tabular}

Keterangan: $\mathrm{Std}=$ standar deviasi, $\mathrm{n}=$ jumlah sampel

Tabel 2 Hasil analisis varians untuk uji kesamaan kekuatan rata-rata kuat rekat geser keempat perlakuan

\begin{tabular}{cccccc}
\hline Sumber & $\begin{array}{c}\text { Derajat } \\
\text { Kebebasan }\end{array}$ & $\begin{array}{c}\text { Jumlah } \\
\text { kuadrat }\end{array}$ & $\begin{array}{c}\text { Rata-rata } \\
\text { Jumlah kuadrat }\end{array}$ & F $_{\text {Hitung }}$ & Simpulan \\
Variasi & 1 & $3.840,543$ & $3,840.543$ & & \\
Rata-rata & 3 & 69,663 & 23.552 & 5,79 & Berbeda \\
Antar perlakuan & 36 & 149,230 & 3.895 & & \\
\hline Jalam perlakuan & 40 & $4.148,326$ & - & - \\
\hline
\end{tabular}

Tabel 3 Uji kesamaan Neuman Keuls kekuatan kuat rekat geser rata-rata kelompok perlakuan dan kontrol

\begin{tabular}{cccc}
\hline Perlakuan & Nilai pengukuran & Nilai tabel Neuman Keuls & Simpulan \\
\hline 1 dengan 3 & 3,44 & 1,35 & Bermakna \\
1 dengan 4 & 1,89 & 1,24 & Bermakna \\
1 dengan 2 & 0,36 & 0,95 & Tidak Bermakna \\
2 dengan 3 & 2,77 & 1,25 & Bermakna \\
2 dengan 4 & 1,87 & 0,83 & Bermakna \\
3 dengan 4 & 1,54 & 0,94 & Bermakna \\
\hline
\end{tabular}

1. Hole berulir+pin berulir, 2.hole berulir+pin tanpa ulir, 3.hole tanpa ulir+pin berulir, 4.hole tanpa ulir+pin tanpa ulir 


\section{Penilaian sisa semen yang merekat pada sayap lempeng logam}

Untuk menentukan sisa semen yang masih merekat pada sayap logam digunakan indeks skor seperti terlihat pada grafik 1 , yaitu sisa semen adesif pada hole ulir+pin ulir hampir sama dengan hole ulir+pin tanpa ulir, lebih banyak dari hole tanpa ulir+pin ulir serta hole tanpa ulir+pin tanpa ulir.

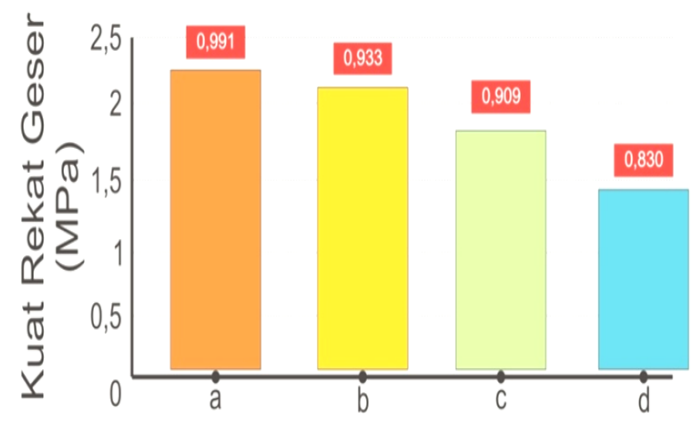

Grafik 1 Skor penilaian sisa bahan perekat yang masih merekat pada sayap lempeng logam (a, hole ulir+pin ulir; b, hole ulir+pin tanpa ulir; c, hole tanpa ulir+pin ulir; d, hole tanpa ulir+pin tanpa ulir).

\section{PEMBAHASAN}

Konsepperawatan gigi dengan metode intervensi minimal dicapai dengan GTJ adesif. pengambilan struktur gigi sehat sebanyak 3-30\%, sedangkan GTJ tradisional membutuhkan pengambilan $63-72 \%$. Kelebihan ini membuat restorasi tersebut menjadi salah satupilihanmenarik bagi pasien muda, terlebih karena kurang menimbulkan sensitivitas setelah pereparasi gigi. Terlepas dari kelebihan tersebut, umumnya penelitian melaporkan tingkat ketahanan restorasiinihanya $70-80 \%$ dengan usia 4-6 tahun. ${ }^{14,15}$

Suatu GTJ adesif dianggap berhasil bila terjadi ikatan yang kuat dan permanen antara permukaan gigi dan logam. Namun dalam menghasilkan suatu ikatan yang kuat,sungguhmerupakan suatu fenomena yang kompleks dan sulit karena permukaan gigi dan permukaan logam memiliki susunan molekul dan karakteristik fisik yang berbeda. ${ }^{16}$

Retensi GTJ adesif sangat kurang, sebagian besar retensi didapat dari kekuatan semen adesif. Oleh karena itu, perlu dipikirkan suatu inovasi, baik pada permukaan gigi maupun pada sayap logam, agar didapatkan suatu retensi yang memadai untuk GTJ adesif. Telah banyak dilakukan modifikasi permukaan sayap logam seperti dengan membuat bentuk mesh, bentuk perforated, dan bentuk kasar karena di-sandblast. Permukaan gigi penyangga dapat dimodifikasi dengan membuat preparasi boks untuk gigi premolar dan molar, sedangkan untuk gigi anterior dapat dibuat preparasi hole. Meskipun demikian,bentukhole saja tidak menjamin diperoleh suatu retensi yang memadai. Oleh karena itu pada preparasi hole perlu dibuat ulir dengan menggunakan fisur bur berulir yang menambah kekasaran pada permukaan preparasi sehingga diperoleh retensi yang maksimal. $^{4,14,15}$

Dari penelitian ini dinyatakan bahwa pembuatan hole yang dimodifikasi dengan ulir memberi retensi yanglebih memadai pada permukaan gigi penyangga namun tidak demikian dengan pin pada sayap logam. Hasilpenelitian ini sesuai dengan pendapat Kaufman dkk yang dikutip oleh Ridwan, yang mengatakan peningkatan kekasaran preparasi dapat menambah besarnya retensi karena adanya peningkatan ikatan mekanis antara bahan semen dan permukaan gigi yang kasar. Terdapat korelasi yang nyata antara kekasaran permukaan preparasi gigi dengan besarnya retensi. $^{4}$

Kekasaran permukaan adalah ketidakteraturan konfigurasi suatu penampang permukaan sehingga retensi mekanis dapat diperoleh dari permukaan preparasi gigi dan permukaan dalam restorasi.Selagi semen masih cair, memasuki kekasaran di kedua permukaan, sehingga setelah keras, semen bertindak sebagai kunci yang memegang erat permukaan tersebut. $^{17}$

Beberapa penelitian telah melaporkan bahwa semen Panavia ${ }^{\mathrm{TM}} \mathrm{F} 2.0$ lebih tinggi kekuatan ikatannya dari Panavia orisinal serta dengan aloi base metal karena memiliki formulasi resin bis-GMA atau 10-methacryloxydecyl dihydrogen phosphate (MDP) yang dapat berikatan secara kimiawi dengan oksida dari nikel, chromium, dan cobalt. Hal ini yang mendasari semen resin adesif Panavia ${ }^{\mathrm{TM}} \mathrm{F} 2.0$ menjadi pilihan dalam penelitian ini. Umumnya semen resin adesif lebih efektif pada permukaan email daripada permukaan dentin. ${ }^{16}$

Uji kuat rekat geser dilakukan setelah 24 jam karena kekuatan ikatan tertinggi dari semen resin adesif terjadi 24 jam setelah aplikasi semen resin adesif, sehingga kegagalan kohesi dapat diminimalkan dengan mengikuti prinsip-prinsip dasar aplikasi dan petunjuk pemakaiannya. ${ }^{19}$

Pada penelitan ini desain preparasi hole ulir+ pin ulir memberi retensi yang lebih baik dibanding kelompok perlakuan yang lain karena semen resin adesif terikat diantara ulir, sehingga membentuk penguncian diantara permukaan gigi penyangga dengan sayap logam.Sedangkan pada desain preparasi hole ulir+pin tanpa ulir, dan hole tanpa ulir+pin ulir kurang memberi retensi, karena retensi hanya diperoleh pada salah satu permukaan.

Sesuai dengan penilaian berdasarkan ARI, sisa semen paling banyak terdapat pada desain hole ulir+ pin ulir, dan paling sedikit pada hole tanpa ulir+pin 
tanpa ulir. Hal ini mungkin disebabkan adanya ulir menambah kekuatan rekat semen adesif.

Disimpulkan bahwadesain preparasi hole berulir+ pinberulirmempunyairetensi yang paling besar. Hal tersebut didukung dengan sisa semen paling banyak terdapat pada permukaan ulir.Berdasarkan hasil ini, perlu dilakukan penelitian lanjut menggunakan jenis semen resin dan bentuk retensi yang lain.

\section{DAFTAR PUSTAKA}

1. Prajitno HR. Ilmu geligi tiruan jembatan, pengetahuan dasar dan rancangan pembuatan. Edisi ke-2. Jakarta: EGC; 1994. p. 119.

2. Ayad MF, Johnston WM, Rosenstiel SF. Influence of tooth preparation taper and cement type on recmentation strength of complete metal crowns. J Prosthet Dent 2009; 102: 354-61

3. Goodacre CJ, Campagni WV, Aquilino SA. Tooth prepration for complete crowns: an art from base and scientific principles. J Prosthet Dent 2001; 85: 363-76

4. Ridwan IA. Pengaruh kekasaran permukaan preparasi gigi terhadap retensi dari mahkota penuh logam cor yang disemen. Jurnal Kedokteran Gigi 1991; 11: 3-4.

5. Shillingburg HT, Hobo S, Whitsett DL. Fundamentals of fixed prosthodontics. Edisi ke-3. Kimberly: Quintessence Publishing Co.Inc.; 1997.p. 539-45.

6. Rosenstiel SF, Land MF, Fujimoto J. Contemporary fixed prosthodontics. $3^{\text {rd }}$ Ed. Mosby; 2001.p. 674-77, 680.

7. Machmud E. Uji beda kekuatan rekat semen resin adhesif pada permukaan logam yang diberi empat macam perlakuan [Karya Tulis Akhir]. Bandung: FKG UNPAD; 2003: 14-25.

8. Barclay CVV, Imsley AD. Fixed and removable prostodontics. $2^{\text {nd }}$ Ed. Churchill. 2001.p. 127-9

9. Creugers NHJ, Kayser AF, van't Hoff MA. A seven-and a-half- year. Survival study of resin-bonded bridges. J Dent Res 1992; 71: 18-22

10. Konings M, Krueger D. Choosing and using permanent luting cement. ADA 2005: 2-4

11. Effect of temporary cements on the shear bond strength of luting cements. J Appl Oral Sci 2010;18: 31 .

12. Phillips RW. Bonding agents and adhesives. Adv Dent Res 1988; 2 (1):152

13. Weiner R. Liners, bases, and cements in clinical dentistry. A review and updates. Dent Today 2003; 22(8): 88-93.

14. El-Mowafy O. Resin bonded fixed partial denture as alternative to conventional fixed treatment. Int J Prosthodont 2003; 16: 60-70.

15. Kern. Clinical long term survival rate of two retainer and single retainer all-ceramic resin-bonded fixed partial denture. Quintessence Int 2005; 36: 141-7.

16. Guler AU, Bulent BEK, Korpulu H, Guler E. Shear bond strength between base metal alloy and restorative materials cemented with adhesives resin: Effect of base metal surface treatment and restorative material 2005; 29 (2): 8-15.

17. Martanto P. Teori dan praktek ilmu mahkota dan jembatan. Bandung: Penerbit Alumni;1981; 2 (1) : 61,119

18. Fracture resistance of re-attached coronal fragments- influence of different adhesive material and bevel preparation. Dent traumatol 2004; 20:159.

19. Watanabe F, Powers JM, Lorey RE. In vitro bonding of prosthodontic adhesives to dental alloys. J Dent Res 1988; 67(2): 479-83. 